\title{
ARTÍCULOS
}

\section{AUTONOMÍAS AÑEJAS EN ESCENARIOS NUEVOS. FUENTES Y DIRECTRICES PARA ANALIZAR ASPIRACIONES POLÍTICAS DE LAS PROVINCIAS EN UN ESCENARIO DE CRISIS: SAN LUÍS POTOSÍ, 1808-1814.}

\author{
Graciela Bernal Ruíz \\ Universidad de Guanajuato \\ gbernal@ugto.mx
}

\begin{abstract}
Resumen: El artículo discute una propuesta para analizar las aspiraciones políticas que manifestaron algunas provincias americanas tras la ausencia del monarca, cuyo carácter autonomista ha sido señalado por la historiografía. Plantea que las Instrucciones elaboradas por las capitales de provincia y enviadas a sus representantes en la península son fuentes de indiscutible valor para conocer esas aspiraciones, entre otras razones, porque a través de ellas hicieron peticiones para fortalecer a sus jurisdicciones. No obstante, algunas de esas peticiones no eran nuevas, por lo que su análisis requiere remontarnos, al menos, al último cuarto del siglo XVIII, cuando diversas medidas implementadas por la Corona llevaron a las ciudades a defender sus prerrogativas. Al ejemplificar esta vinculación con el caso de San Luis Potosí, se muestra que los grupos de poder local habían realizado diversos intentos para buscar cierta autonomía de la capital del virreinato, y aprovecharon la coyuntura de 1808 para intentar concretarla.
\end{abstract}

Palabras clave: Autonomía, aspiraciones políticas, fuentes, San Luis Potosí.

Tittle: OLD AUTONOMIES IN NEW SCENARIOS. SOURCES AND GUIDELINES TO ANALYZE POLITICAL ASPIRATIONS IN A CRISIS SCENARIO: SAN LUIS POTOSÍ, 1808-1814.

\begin{abstract}
The aim of this article is to propose an analysis of the political aspirations manifested in some American provinces after their monarch's absence. Provinces whose autonomous character has been pointed out by historiography. Furthermore, it argues that the Instrucciones made by the provinces' capitals-which were sent to their political representatives in Spain-are sources of immense value to understand these aspirations because petitions were made by these means in order to strengthen their jurisdiction. However, some of these requests were not new, which requires us to go back to at least, the last quarter of the eighteenth century, when several measures taken by the Spanish Crown forced different cities to defend their privileges. Linking the aforementioned events with the situation in San Luis Potosí, demonstrates that groups of local power had made various attempts to gain certain autonomy from the viceroyalty's capital, and therefore, they took advantage of the 1808 political climate to try and realize it.
\end{abstract}

Keywords: Autonomy, political aspirations, sources, San Luis Potosí.

Recibido: 27-07-2020

Aceptado: $14-08-2020$

Cómo citar este artículo: BERNAL RUIZ, Graciela. Autonomías añejas en escenarios nuevos. Fuentes y directrices para analizar aspiraciones políticas de las provincias en un escenario de crisis: San Luís Potosí, 1808-1814. Naveg@mérica. Revista electrónica editada por la Asociación Española de Americanistas [en línea]. 2020, n. 25. Disponible en: <http://revistas.um.es/navegamerica>. [Consulta: Fecha de consulta]. ISSN 1989-211X. 


\section{Presentación. La problemática y el camino recorrido}

Los eventos que se presentaron en 1808 en la monarquía española tuvieron una trascendencia indiscutible para el conjunto de sus territorios porque, además, se enmarcaron en un convulso contexto político que envolvía buena parte de los escenarios europeos y sus posesiones americanas, y ya habían tenido sus primeros desenlaces con las independencias de Haití y los Estados Unidos de Norteamérica.

La historiografía se ha ocupado del tema de manera cada vez más constante al menos desde hace un par de décadas ${ }^{1}$. Esta producción aumentó en la medida que se acercaban las conmemoraciones de las independencias de Hispanoamérica, estableciendo una conexión más estrecha entre los eventos que tuvieron lugar en la península y los que se presentaron en los territorios americanos. Esa conexión se estableció principalmente con dos puntos generales; por un lado, con los intentos fallidos o exitosos- de crear juntas de gobierno, y por el otro, con los posteriores movimientos armados. Lo anterior en el entendido de que formaron parte de un mismo proceso que tuvo como punto de partida la ocupación de la península por las tropas francesas, y que, con un desarrollo marcado por las particularidades de cada región, casi en su totalidad derivó en las independencias de los países americanos ${ }^{2}$.

Los temas de estudio que se han desprendido de estos eventos son muchos y han enriquecido el debate historiográfico, así como el conocimiento de esos años que se presentaron tan convulsos en diferentes planos. Todos ellos han abrevado de una variedad de fuentes documentales para su análisis y explicación, entre las que destacan las que produjeron las instituciones jurídico-políticas y los grupos de poder que vieron en esta coyuntura la posibilidad de tener una influencia política y económica en mayor grado y, en ese sentido, obtener amplios beneficios. La importancia de este tipo de fuentes para analizar el proceso resulta natural, porque fueron años en que los territorios peninsulares y de ultramar debatían una nueva manera de relacionarse con la monarquía, y esto demandó nuevas instituciones que actuaran en nombre del rey ausente, así como de nuevos ordenamientos y formas de participación política. La máxima expresión de todo esto fue la Constitución de Cádiz de 1812, que se publicó luego de dos años de intensos debates en las Cortes que había iniciado sus sesiones en septiembre de 1810. Pero no menos importante

\footnotetext{
${ }^{1}$ Los primeros esfuerzos en esta línea, de manera más o menos conjunta, fueron CASTILLO, Francisco. Las Cortes de Cádiz y la imagen de América: la visión etnográfica y geográfica del Nuevo Mundo. Cádiz: Universidad de Cádiz, 1994; FERRER, Manuel. La constitución de Cádiz y su aplicación en la Nueva España. México: UNAM; IIJ, 1993; RIEU-MILLAN, Marie-Laure. Los diputados americanos en las Cortes de Cádiz: igualdad o independencia. Madrid: CSIC, 1990, CHUST, Manuel. La cuestión nacional americana en las Cortes de Cádiz, 1810-1814. Valencia: Centro Francisco Tomás y Valiente; UNED Alzira; Fundación Instituto Historia Social; UNAM; IIH, 1999.

${ }^{2}$ La bibliografía es vasta, aquí sólo anotamos los trabajos más representativos, CHUST, Manuel. (coord.). La eclosión juntera en el mundo hispano. México: El Colegio de México; FCE, 2007; ÁVILA, Alfredo y Pedro PÉREZ HERRERO (coords.). Las experiencias de 1808 en Iberoamérica. México: Universidad de Alcalá, UNAM, 2008. Sobre la importancia que ese proceso significó para los movimientos armados americanos, véase sobre todo RODRÍGUEZ, Jaime. Las independencias de la América española. México: FCE; El Colegio de México, 1996, y GUERRA, Francois-Xavier. Modernidad e independencia. México: FCE, 2000.
} 
son la variedad de leyes y decretos que se dictaron, antes y después de la constitución gaditana, para atender los diferentes ámbitos del gobierno y su administración.

En ese marco, una línea importante de investigación son las prácticas políticas de los americanos, que por primera vez tenían la posibilidad de participar de los debates para definir el rumbo de la monarquía, pero, sobre todo, de influir de una manera más efectiva sobre el rumbo que tomarían sus propias jurisdicciones con respecto a las capitales de los virreinatos, y del papel que ellos mismos tendrían en este nuevo camino que ampliaba las aspiraciones que venían manifestando de manera clara desde las últimas décadas del siglo XVIII. El presente artículo tiene como objetivo mostrar algunas de las fuentes que consideramos más importantes para conocer esas aspiraciones y las estrategias que siguieron los grupos de poder local para poder alcanzarlas. Para ello, primero planteamos el escenario general de Nueva España, para después realizar un análisis más puntual del caso de San Luis Potosí. Señalaremos los repositorios en donde se localizan esas fuentes, así como la manera de acercarse a ellas, metodológicamente hablando.

Por principio de cuentas, es importante tener presente que las expectativas de los americanos se manifestaron de manera amplia a partir de una coyuntura: la ausencia del rey que obligó a la creación de nuevas instituciones que actuasen en su ausencia, lo que no estuvo exento de debates y conflictos. En ese marco la Junta Central Gubernativa del Reino les otorgó un par de concesiones a través de la real orden de 22 de enero de 1809. La primera de ellas -la más analizada y debatida- fue la representación, al conceder a los americanos el derecho a elegir un representante por cada virreinato y capitanía general, que después fue ampliada a una representación por provincia ${ }^{3}$. La segunda -menos analizada en la historiografía a pesar de su importancia- fue que las ciudades elaboraran Instrucciones para enviar a sus representantes; en ellas debían plantear los puntos que consideraran más importantes para lograr la prosperidad de sus provincias.

Las respuestas de los americanos a estas concesiones se convierten en documentos de indiscutible valor para el objetivo de este artículo; en primer lugar, porque a través de ellas podemos conocer las estrategias que utilizaron para hacerse presentes en uno y otro lado del Atlántico; en segundo, por también muestran de manera clara sus aspiraciones y, en esa línea, la autonomía a la que aspiraban, y que esa autonomía era más evidente respecto a sus capitales virreinales que de la península. Algunas de esas respuestas y estrategias se pueden identificar en los amplios debates que en gran medida quedaron registrados en los Diarios de sesiones de las Cortes, pero, sobre todo, en las actas de cabildo, protocolos notariales, actas de Diputaciones provinciales y correspondencia oficial, por mencionar los más importantes, y que se pueden consultar en diferentes acervos que iremos señalando a lo largo del texto.

\footnotetext{
${ }^{3}$ Los diputados electos para participar en la Junta Central no alcanzaron a llegar porque ésta fue disuelta a finales de enero de 1810 dando paso a la Regencia del Reino, la que convocó a Cortes y amplió la representación americana; mediante decreto de 14 de febrero de 1810 otorgaba la representación por provincia.
} 
Estas fuentes han sido aprovechadas en la historiografía mayoritariamente para analizar la representación, algo que resulta lógico porque hasta ese momento los americanos sólo se habían hecho escuchar en la península a través de procuradores -personajes que promovían beneficios buscados por las ciudades- ${ }^{4}$, pero, sobre todo, por la importancia que esto trajo para las prácticas políticas en todos los territorios de la monarquía al generar una movilización nunca antes vista en la mayoría de ellas: se realizaron elecciones en diferentes niveles y esto llevó a que los grupos de poder local buscaran hacerse con esa representación.

Las principales fuentes para analizar el papel de los diputados americanos y su trascendencia en los debates sobre temas cruciales para la monarquía son los diarios de sesiones de las Cortes, pues ellos registran sus intervenciones, los temas que debatieron y cómo lo hicieron, las comisiones de las que formaron parte, las propuestas que plantearon y defendieron; registran una participación dinámica e intensa, que no pocas veces llevó a que sus contrapartes peninsulares los acusaran de autonomistas ${ }^{5}$. Las actas de sesiones de las Cortes evidencian, como han mostrado algunos estudios, que los diputados trabajaron en uno y otro sentido, es decir, debatieron para definir el rumbo de la nación, pero también -como no podía ser de otra manera-, velaban por los intereses de sus provincias, y casi podría decirse que de sus ciudades. Los debates han sido seguidos de manera puntual por autores como Manuel Chust y Marie Rieu-Millán, quienes evidencian el importante papel que en esos debates tuvieron los diputados americanos ${ }^{6}$.

Los diarios también contienen información para analizar el tema que nos interesa en este artículo, las aspiraciones de las provincias y su larga data, que se ha mencionado de manera amplia en la historiografía, pero su análisis ha despertado menor interés a pesar de que éstas y otras fuentes contienen información muy valiosa para mostrarlo. Por ejemplo, la documentación nos permite ver que, al mismo tiempo que varias ciudades elaboraban las instrucciones que enviarían a sus representantes, algunos diputados que actuaron como suplentes en las Cortes electos entre los americanos que en ese momento radicaban en Cádiz- solicitaron varios de los puntos que se plantearían en esos documentos: igualdad de representación, libertad de cultivos, ampliación de la libertad de comercio, etc., algo que muestra de manera clara que esas aspiraciones no eran nuevas y que eran

\footnotetext{
${ }^{4}$ Las ciudades recurrían a procuradores para tratar de alcanzar algunos beneficios; por lo regular se trataba de asuntos muy específicos. Además de esto, una diferencia sustancial con la nueva representación a través de diputados era el carácter electivo de estos últimos. Véase Iván ESCAMILLA, Iván. La representación política en Nueva España: del antiguo régimen al advenimiento de la nación. Historias. May./ago. 2000, n. 46, pp. 23-43.

${ }^{5}$ Los Diarios de sesiones de las Cortes pueden consultarse, entre otros sitios, en la Biblioteca Cervantes. [Consulta: 24-06-2020]. Disponibles en <http://www.cervantesvirtual.com/obravisor/coleccion-de-los-decretos-y-ordenes-que-han-expedido-las-cortes-generales-y-extraordinariasdesde-su-instalacion-en-24-de-septiembre-de-1810-hasta-igual-fecha-de-1811--0/html/ > .

${ }^{6}$ RIEU-MILLAN, Marie- Laure. Los diputados americanos en las Cortes de Cádiz... Op. cit., y CHUST, Manuel. La cuestión nacional americana en las Cortes de Cádiz... Op. cit.
} 
compartidas por diferentes actores ${ }^{7}$.

Por otra parte, debemos señalar que esta coyuntura generó una amplia expectativa entre los americanos, quienes esperaban que sus peticiones fueran atendidas y para ello incorporaron de manera rápida los nuevos lenguajes políticos. En ese sentido, debemos tener presente que se estaban presenciando importantes cambios en medio de una crisis que rebasaba los límites de la monarquía española. Es aquí en donde se conjugan antiguas y nuevas prácticas que fueron aprovechadas por las capitales de provincia, cuyos actores políticos tenían en mente dos escenarios interrelacionados que requerían estrategias distintas pero complementarias: el peninsular y el propiamente americano, que a su vez se enmarcaban en otros eventos que no tardaron en presentarse, como los movimientos armados. Todo ello generó una gran cantidad de documentación que se encuentra resguardada en acervos locales, nacionales e internacionales, y que se convierten en invaluables fuentes para reconstruir este proceso.

Para el tema que abordamos en este artículo, sin lugar a duda, las actas de cabildo se encuentran entre las fuentes de mayor valor porque las instituciones que actuaban en nombre del rey dejaron a los ayuntamientos la tarea de realizar las elecciones, otorgar poderes y elaborar las Instrucciones que enviarían a sus representantes; algo que no resulta raro en tanto eran las instituciones más cercanas a las poblaciones y las que conocía de manera más puntual las dinámicas, necesidades e intereses locales. En esas actas encontramos el proceso de las elecciones que, en mayor o menor medida, registran los nombres que se propusieron y los que resultaron electos mediante los sorteos correspondientes; en algunos casos se registra información sobre las características de los individuos propuestos, así como su origen. También contamos con los protocolos notariales, en donde se pueden encontrar las actas de las elecciones, además de los poderes enviados a quien resultó electo por la Nueva España en el proceso de 1809, y a quienes representaron a las provincias a partir de 1810.

Asimismo, en las actas de cabido podemos encontrar indicios sobre cómo imaginaban la representación; dicho de otra manera, esperaban que sus diputados promovieran de manera efectiva todo aquello que asentaban en sus Instrucciones. En ese sentido, acordar qué se incluiría en ellas y cómo se presentarían resultaba crucial para quienes vieron en esta coyuntura la posibilidad de concretar sus aspiraciones autonomistas, porque además se presentaba en un contexto en que se introducían nuevas prácticas, como la elección de diputados americanos y la oportunidad de plantear de manera conjunta los puntos que se consideraran importantes para la prosperidad de la provincia, lo que sin duda generó amplias expectativas, sobre todo entre los grupos de poder de sus capitales.

En el caso que analizamos, el cabildo de San Luis Potosí registró cómo procedió para elaborar sus Instrucciones, lo que nos permite saber que optó por la inclusión al buscar y alcanzar de manera rápida un consenso sobre los temas que debían

\footnotetext{
${ }^{7}$ Debió entablarse una fluida comunicación transatlántica para el tema de la representación mientras llegaban los propietarios, pero es evidente que quienes actuaron como suplentes se apropiaron rápidamente de la discusión, lo cual, asumimos, obedece a que estaban familiarizados con muchas de las demandas que se planteaban en las Instrucciones.
} 
incluirse en ese documento: se formó una comisión que hizo una primera propuesta y pidió su parecer a una variedad de letrados y funcionarios de la ciudad. Por esta razón, además del documento que enviaron al diputado por Nueva España, las actas de cabildo también contienen valiosa información que nos permite saber lo que se quedó en el tintero: las respuestas de esos individuos ${ }^{8}$. Ambas fuentes, Instrucciones y estas respuestas, nos brindan un escenario puntual de las aspiraciones de los grupos de poder local, así como de las estrategias que utilizaron para elaborar un documento que contuviera peticiones con posibilidad de ser atendidas. Es en estos documentos que se pueden identificar signos claros de autonomía; lo son para San Luis Potosí, pero creemos que también para muchos otros casos. Mostramos estas fuentes a continuación.

\section{Instrucciones de las provincias a sus diputados: fuentes para conocer las aspiraciones políticas de los americanos}

Luego de elegir a sus diputados que participarían en la Junta Central Gubernativa del Reino, las diferentes provincias americanas enfocaron sus esfuerzos, con mayor o menor intensidad, en elaborar las Instrucciones que, junto con amplios poderes, debían enviar a sus representantes en la península; así lo señalaba la real orden de 22 de enero de 1809. Algunos de estos documentos han sido recopilados y publicados en un par de obras: en 2005 las instrucciones que elaboraron las provincias novohispanas ${ }^{9}$, y en 2008 las de Nueva Granada y Venezuela ${ }^{10}$. Para el caso novohispano, algunos extractos de ellas habían sido publicados hace varias décadas por Enrique Florescano e Isabel Gil ${ }^{11}$. En todos los casos se resalta su importancia para conocer las dinámicas regionales, como también lo señaló Francois-Xavier Guerra en su libro Modernidad e independencia, al decir que algunas ciudades habían elaborado "verdaderos tratados sintéticos sobre el estado y necesidades de la región", y al referirse al caso de San Luis Potosí, señala que sus Instrucciones "nos hacen percibir una región que parece en plena

\footnotetext{
${ }^{8}$ Las respuestas de todos los individuos consultados se localizan en el Archivo Histórico del Estado de San Luis Potosí (en adelante AHESLP), Ayuntamiento de San Luis Potosí, Actas de cabildo de 1809. Aquí también están las Instrucciones que enviaron al Diputado por Nueva España. Este último documento, también se localiza en Archivo General de la Nación (en adelante AGN), Historia, vol. 417.

${ }^{9}$ ROJAS, Beatriz. Documentos para el estudio de la cultura política de la transición: juras, poderes e instrucciones, Nueva España y la Capitanía General de Guatemala, 1808-1820. México: Instituto Mora, 2005. Como resultado de una investigación personal, se localizaron esos documentos en diferentes acervos, además de otros documentos complementarios, principalmente "adiciones" que en los siguientes años se hicieron a esas Instrucciones, en: el AGN, Historia 417. En el Archivo General de Indias (en adelante AGI), Indiferente General 1354, 1358 y 1524. En el Archivo del Congreso de los Diputados de Madrid (en adelante ACDM), Serie General, legajo 4, núm. 29; legajo 4, núm. 134; legajo 19, núm. 9; y legajo 20, núm. 10.

${ }_{10}$ ALMARZA, Angel y Armando MARTíNEZ (eds.). Instrucciones para los diputados del Nuevo Reino de Granada y Venezuela ante la Junta Central Gubernativa de España e Indias. Bucaramanga: Universidad Industrial de Santander, 2008.

${ }^{11}$ FLORESCANO, Enrique y GIL, Isabel. Descripciones económicas generales de Nueva España, 1784-1817. México: SEP; INAH, 1973, y Descripciones económicas regionales de Nueva España. Provincias del norte, 1790-1814. México: INAH; SEP, 1976.
} 
expansión, con elites llenas de dinamismo y de iniciativa"12.

Estos señalamientos han tenido escaso eco en la historiografía, y fue lo que desde hace varios años nos motivó a ocuparnos de las instrucciones de una jurisdicción a la que hemos dedicado varios años de investigación, cuyo estudio integral se publicó en una obra reciente ${ }^{13}$. Siguiendo los pasos marcados por Guerra, se localizaron las instrucciones en el Archivo General de la Nación, en un legajo que contenía las Instrucciones de varias provincias novohispanas ${ }^{14}$. Otras Instrucciones fueron localizadas en el Archivo General de Indias ${ }^{15}$, y unas más en el Archivo del Congreso de los Diputados de Madrid ${ }^{16}$. Estos repositorios también resguardan información adicional para el tema, como la correspondencia que establecieron las provincias con sus diputados, en donde se tocaban temas concernientes a las Instrucciones, los poderes y algunos temas relacionados con el desarrollo de las sesiones de las Cortes. Por otra parte, con toda seguridad los archivos locales también resguardan copias de estas Instrucciones, como es el caso de San Luis Potosí ${ }^{17}$.

Al realizar un análisis comparativo en cuanto a la fecha de los documentos asumimos que es la fecha en que se terminaron- y de la extensión de cada uno de ellos, se puede apreciar que las primeras Instrucciones están fechadas en el segundo semestre de ese mismo año: Texas y Nueva Filipinas, San Luis Potosí, Guanajuato, Oaxaca y Zacatecas, y que, salvo Guanajuato, se cuentan entre los documentos más extensos que elaboraron los novohispanos. Otras Instrucciones extensas son las de Arizpe (marzo de 1810) y Coahuila (1811). Durante los años de 1812 a 1814 algunas provincias presentaron sus primeras Instrucciones, adiciones o documentos más extensos, como fueron los casos de Guadalajara, Yucatán, Puebla y Querétaro ${ }^{18}$.

Lo primero que interesa resaltar es la extensión de algunas de ellas y la relativa

\footnotetext{
${ }^{12}$ GUERRA, Francois-Xavier. Modernidad e independencia... Op. cit., pp. 206-207 y 215.

${ }^{13}$ BERNAL RUIZ, Graciela. Sin quedarle qué envidiar a la metrópoli de México. Las aspiraciones políticas de una provincia novohispana, San Luis Potosí, 1786-1821. Zamora: El Colegio de Michoacán; El Colegio de San Luis; Universidad de Guanajuato; Universidad Jaume I, 2019. Anteriormente se publicaron otros trabajos como: El ayuntamiento de San Luis Potosí durante la crisis monárquica. Expectativas y realidades (1808-1814). En: HENSEL, Silke (coord.). Constitución, poder y representación. Dimensiones simbólicas del cambio político en la época de la independencia mexicana. Madrid: Iberoamericana; Frankfurt am Main: Vervuert; México: Bonilla Artigas, 2011, pp. 241-275 y En búsqueda de una descentralización. San Luis Potosí en la coyuntura de la crisis monárquica. En: ORTIZ, Juan y FRASQUET, Ivana (eds.). Jaque a la Corona. La cuestión política en las independencias Iberoamericanas. Castellón: Universitat Jaume I, 2010, pp. 57-77.

${ }^{14}$ AGN, Historia, 417, además de San Luis Potosí, en este legajo se encuentran las de: Oaxaca, Arizpe, México, Guadalajara, Guanajuato, Puebla y Valladolid.

${ }^{15} \mathrm{AGI}$, Indiferente General 1354: las instrucciones de Chiapas, Puebla, Veracruz y Yucatán.

${ }^{16}$ ACDM, Serie General, legajo 20, núm. 10, las instrucciones de Querétaro, legajo 19, núm. 9 las instrucciones de Nuevo México.

17 AHESLP, Ayuntamiento de San Luis Potosí, Actas de cabildo, 24 de octubre de 1809, Instrucción que en cumplimiento de la Real Orden de 22 de enero del presente año de 1809, librada por la Suprema Junta Central depositaria de la autoridad Soberana el Ayuntamiento de SLP al Exmo. Sr. D. Miguel de Lardizábal, diputado representante por la Nueva España y vocal de dicha Suprema Junta.

${ }_{18}$ Se encuentran en AGI, Indiferente 1354 y 1358 . Querétaro formaba parte de la intendencia de México, pero exigió y se le concedió representación.
} 
rapidez con que se elaboraron, sobre todo si consideramos que hubo provincias que pedían más tiempo para pensar y elaborar documentos de vital importancia para sus provincias, como fue el caso de Guadalajara $^{19}$, y que otras presentaron propuestas demasiado generales, en las que ratificaban su lealtad al rey, se vanagloriaban de que la Junta Central hubiese declarado la igualdad de todos los territorios de la monarquía y, sin entrar en mayor detalle, mencionaban alguna necesidad de sus provincias; esto fue así con México, Guanajuato y Valladolid ${ }^{20}$.

Un segundo aspecto en el que reparamos es que las Instrucciones más extensas, y sobre todo las que se elaboraron con mayor prontitud -1809-, eran de provincias alejadas de la capital del virreinato. Esto cobra relevancia cuando observamos los asuntos que abordaban, y que se enuncian en el Cuadro 1: obispado, repartimiento de mercancías y varios temas vinculados de manera directa con la actividad económica (recordemos que se buscaba el fomento de las provincias), como el comercio, consulados, puerto, repartimientos, siembra de ciertos productos, y establecimiento de fábricas. Otros puntos se relacionan con contribuciones: como el derecho de pulperías, los tributos y las alcabalas. También aparecen temas relacionados con instituciones, de manera específica, la supresión de intendencia, o la creación de obispados, universidades y escuelas de primeras letras.

\begin{tabular}{|c|c|c|c|}
\hline \multicolumn{4}{|c|}{ INSTRUCCIONES DE PROVINCIAS DE NUEVA ESPAÑA ELABORADAS EN 1809} \\
\hline Zacatecas $^{21}$ & Texas $^{22}$ & Oaxaca $^{23}$ & San Luis Potosí \\
\hline
\end{tabular}

19 AGN, Historia, 417, 9 de febrero de 1810, Poder que otorga el ayuntamiento de Guadalajara al Exmo. Sr. Diputado del Reino Miguel de Lardizábal y Uribe para que lo represente en la Junta Suprema Gubernativa del Reino. Las instrucciones más extensas se localizan en ACDM, Serie General, leg. 4, núm. 49, 15 de enero de 1812, Proposiciones del Sr. Uría acerca de que se erija en la capital de Guadalajara de la América Septentrional un juzgado de Acordada con las facultades que expresa, y AHÍ 1354.

${ }^{20}$ AGN, Historia, vol. 417, 19 de octubre de1809, Puntos que forman la Instrucción que por ahora puede ministrar el ayuntamiento de la ciudad de Santa Fe Real y Minas de Guanajuato al Exmo. Sr. d. Miguel de Lardizábal y Uribe, vocal de la Junta Suprema Central Gubernativa de España e Indias; AGN, Historia, vol. 417, 1 de febrero de 1810, Instrucciones del ayuntamiento de Valladolid de Michoacán bajo cuyo seguro rumbo deberá gobernarse en lo sucesivo el Sr. diputado general del Reino.

${ }^{21}$ En este caso, varios ayuntamientos de Zacatecas presentaron por separado sus instrucciones: Fresnillo, Jerez, Zacatecas y Pinos; aquí se concentran las peticiones en general, en el entendido de que requiere de un análisis puntual. Instrucciones de los ayuntamientos de la provincia de Zacatecas (junio-julio de 1809), en ROJAS, Beatriz. Documentos para el estudio de la cultura política de la transición.... Op. cit., pp.115-136. En 1814 el diputado por esta provincia, José Miguel Gordoa, presenta un solo documento los puntos que, señala, expuso en las Cortes en 1811 y 1812, AGl, Indiferente, 1354.

${ }^{22}$ Instrucciones de las provincias de Texas y Nueva Filipinas, 8 de agosto de 1809, en ROJAS, Beatriz. Documentos para el estudio de la cultura política de la transición... Op. cit, pp. 137-144.

${ }^{23}$ AGN, Historia, Vol. 417, exp. s/n, fojas 308-376, 18 de octubre de 1809. Instrucción que el llustre ayuntamiento de esta ciudad de Antequera, Valle de Oaxaca forma sobre los puntos que quiere se promuevan por el Exmo. Sr. d. Miguel de Lardizábal como en quien ha recaído el empleo vocal de la Suprema Junta Central Gubernativa, y ministro del Supremo Consejo de Indias, a fin de que como tan interesantes a esta provincia se conliga su solicitud.

${ }^{24}$ AGN, Historia, 417, Instrucción que en cumplimiento de la Real Orden de 22 de enero del presente año de 1809, librada por la Suprema Junta Central depositaria de la autoridad Soberana el 


\begin{tabular}{|c|c|c|c|}
\hline Junio-julio & 8 de agosto & 18 de octubre & 24 de octubre \\
\hline $\begin{array}{l}\text { Impulsar la } \\
\text { agricultura, industria } \\
\text { y comercio }\end{array}$ & $\begin{array}{l}\text { Fortalecer a la } \\
\text { figura del } \\
\text { gobernador }\end{array}$ & Fomento de la grana & $\begin{array}{l}\text { Erección de un } \\
\text { obispado }\end{array}$ \\
\hline $\begin{array}{l}\text { Establecer escuelas } \\
\text { de primeras letras }\end{array}$ & $\begin{array}{l}\text { Ampliar los } \\
\text { efectivos militares }\end{array}$ & Restablecer los repartimientos & $\begin{array}{l}\text { Establecimiento de } \\
\text { una fábrica de puros y } \\
\text { cigarros }\end{array}$ \\
\hline $\begin{array}{l}\text { Liberar del pago de } \\
\text { tributo a } \\
\text { trabajadores } \\
\text { mineros }\end{array}$ & $\begin{array}{l}\text { Poblar e impulsar } \\
\text { el fomento de la } \\
\text { provincia }\end{array}$ & Suprimir el plan de Intendencias & $\begin{array}{l}\text { Habilitación de un } \\
\text { puerto en Soto la } \\
\text { Marina }\end{array}$ \\
\hline $\begin{array}{l}\text { Establecer un } \\
\text { sueldo para } \\
\text { subdelegados }\end{array}$ & $\begin{array}{l}\text { Que las misiones } \\
\text { se conviertan en } \\
\text { poblaciones } \\
\text { civiles }\end{array}$ & $\begin{array}{l}\text { Que el piquete de auxilio para } \\
\text { jueces se componga de soldados } \\
\text { del batallón y que cese la pensión } \\
\text { para quitar al público este } \\
\text { gravamen }\end{array}$ & $\begin{array}{l}\text { Repartimiento de } \\
\text { tierras y venta de ellas } \\
\text { en enfiteusis }\end{array}$ \\
\hline \multirow[t]{2}{*}{$\begin{array}{l}\text { Establecimiento de } \\
\text { Sociedades } \\
\text { Económicas del } \\
\text { País } \\
\end{array}$} & $\begin{array}{l}\text { Apertura del } \\
\text { puerto de } \\
\text { Matagorda }\end{array}$ & $\begin{array}{l}\text { Librar la pensión del cabezón que } \\
\text { pagan las tiendas de pulpería }\end{array}$ & $\begin{array}{l}\text { Permiso a los } \\
\text { subdelegados para el } \\
\text { repartimiento de } \\
\text { mercancías } \\
\end{array}$ \\
\hline & $\begin{array}{l}\text { Controlar la } \\
\text { emigración de la } \\
\text { Luisiana }\end{array}$ & $\begin{array}{l}\text { Que a sus comerciantes se les } \\
\text { exonere de juramento que se les } \\
\text { exime a quienes compran con } \\
\text { indios para el cobro de alcabalas, } \\
\text { estando como están exentos de } \\
\text { ella }\end{array}$ & $\begin{array}{l}\text { Establecer fábrica de } \\
\text { efectos con materias } \\
\text { primas }\end{array}$ \\
\hline $\begin{array}{l}\text { Libertad para vender } \\
\text { los frutos de la tierra } \\
\text { (mezcal) }\end{array}$ & $\begin{array}{l}\text { Establecer una } \\
\text { comandancia y } \\
\text { maestranzas }\end{array}$ & $\begin{array}{l}\text { Que no se graven más los } \\
\text { propios para que se destinen a } \\
\text { obras públicas }\end{array}$ & $\begin{array}{l}\text { Suprimir el real } \\
\text { derecho de pulperías }\end{array}$ \\
\hline $\begin{array}{l}\text { Venta del tabaco en } \\
\text { rama }\end{array}$ & $\begin{array}{l}\text { Establecer una } \\
\text { intendencia }\end{array}$ & $\begin{array}{l}\text { Que se otorguen ejidos en la } \\
\text { ciudad para la cría de ganado }\end{array}$ & $\begin{array}{l}\text { Suprimir los tributos } \\
\text { de indios, mulatos y } \\
\text { castas }\end{array}$ \\
\hline \multirow[t]{4}{*}{$\begin{array}{l}\text { Mejorar los ingresos } \\
\text { de los curas con el } \\
\text { diezmo }\end{array}$} & $\begin{array}{l}\text { Establecer } \\
\text { fábricas }\end{array}$ & Crear un Consulado & $\begin{array}{l}\text { Reformar el honorario } \\
\text { de administradores y } \\
\text { receptores de } \\
\text { alcabalas }\end{array}$ \\
\hline & Fundar hospitales & Fundar la Universidad de Oaxaca & $\begin{array}{l}\text { Reconocer los méritos } \\
\text { y servicios de los } \\
\text { empleados } \\
\text { americanos }\end{array}$ \\
\hline & & & $\begin{array}{l}\text { Nombramiento de } \\
\text { intendente }\end{array}$ \\
\hline & & & $\begin{array}{l}\text { Celebración de un } \\
\text { Concilio nacional }\end{array}$ \\
\hline
\end{tabular}

Cuadro 1: Instrucciones de provincias de Nueva España elaboradas en $1809^{25}$. Fuente: AGN, Historia, vol. 417.

Ayuntamiento de SLP al Exmo. Sr. D. Miguel de Lardizábal, diputado representante por la Nueva España y vocal de dicha Suprema Junta, 24 de octubre de 1809; y AHESLP, Ayuntamiento de San Luis Potosí, Actas de cabildo de 1809.

${ }^{25}$ Este año también están fechas las Instrucciones de Guanajuato (19 de octubre), que se limitaron a pedir que América fuese considerada como parte integrante del reino y no como Colonia, y que, en consecuencia, España sea considerada igual que España, sin distinción alguna, siendo para ambas una misma legislación, uno el honor, una la estimación y todo uno sin diferencia del mismo modo que lo son los todos los naturales de las Provincias de España. 
Como se aprecia en el Cuadro 2, varios de esto temas también están presentes en las Instrucciones que se elaboraron en 1810, aunque en estas últimas destacan solicitudes para establecer tribunales de justicia y para atender problemáticas de las fronteras, justamente en provincias del norte del virreinato.

\begin{tabular}{|c|c|c|c|}
\hline \multicolumn{4}{|c|}{ INSTRUCCIONES DE PROVINCIAS DE NUEVA ESPAÑA ELABORADAS EN 1810} \\
\hline $\begin{array}{c}\text { Arizpe }^{26} \\
12 \text { de marzo }\end{array}$ & \begin{tabular}{|c|} 
Puebla $^{21}$ \\
$\mathbf{3 0}$ de mayo
\end{tabular} & $\begin{array}{c}\text { Nuevo Reino de } \\
\text { León }{ }^{28} \\
2^{\circ} \text { de julio }\end{array}$ & $\begin{array}{c}\text { Veracruz }^{29} \\
14 \text { de diciembre }\end{array}$ \\
\hline $\begin{array}{l}\text { Fijar de manera clara } \\
\text { la demarcación } \\
\text { geográfica de Sonora } \\
\text { y Sinaloa y de sus } \\
\text { productos }\end{array}$ & $\begin{array}{l}\text { Que los oficios de los cabildos } \\
\text { sean electivos y por tres años }\end{array}$ & $\begin{array}{l}\text { Establecer una } \\
\text { Real Audiencia }\end{array}$ & $\begin{array}{l}\text { Variar el método de } \\
\text { elección de } \\
\text { representantes para } \\
\text { que participen todos } \\
\text { los padres de familia }\end{array}$ \\
\hline $\begin{array}{l}\text { Establecer de un } \\
\text { puerto para el libre } \\
\text { comercio }\end{array}$ & $\begin{array}{l}\text { Que no se divida el obispado, y } \\
\text { que se ajuste la dotación de } \\
\text { párrocos }\end{array}$ & $\begin{array}{l}\text { Libertad para } \\
\text { fabricar cigarros }\end{array}$ & $\begin{array}{l}\text { Promover la creación } \\
\text { de escuelas de las } \\
\text { artes y ciencias útiles }\end{array}$ \\
\hline $\begin{array}{l}\text { Erigir una catedral y } \\
\text { seminario de jóvenes }\end{array}$ & $\begin{array}{l}\text { Erigir una universidad literaria, } \\
\text { "igual da la de México", y el } \\
\text { establecimiento de una cátedra } \\
\text { de ciencia política y } \\
\text { económica, y aumento de } \\
\text { escuelas de primeras letras }\end{array}$ & $\begin{array}{l}\text { Libre ejercicio del } \\
\text { comercio }\end{array}$ & Dividir obispados \\
\hline $\begin{array}{l}\text { Mejorar la dotación } \\
\text { de los párrocos y su } \\
\text { jurisdicción }\end{array}$ & $\begin{array}{l}\text { Aprobar una dotación para } \\
\text { subdelegados, o que se } \\
\text { nombren alcaldes mayores } \\
\text { letrados con sueldo fijo }\end{array}$ & $\begin{array}{l}\text { Que los americanos } \\
\text { y peninsulares } \\
\text { obtengan las } \\
\text { mismas gracias } \\
\text { para ocupar cargos }\end{array}$ & $\begin{array}{l}\text { Aumentar los } \\
\text { beneficios } \\
\text { eclesiásticos }\end{array}$ \\
\hline $\begin{array}{l}\text { Aprovechar la riqueza } \\
\text { de la tierra para el } \\
\text { plantío de algodón }\end{array}$ & $\begin{array}{l}\text { Que se nombren intendentes } \\
\text { con acreditados conocimientos } \\
\text { en ciencia política económica, } \\
\text { y valorar si este cargo es } \\
\text { compatible con el de } \\
\text { gobernador militar y jefe de } \\
\text { brigada }\end{array}$ & $\begin{array}{l}\text { Fomentar la fábrica } \\
\text { de cigarros de } \\
\text { Monterrey }\end{array}$ & $\begin{array}{l}\text { Mejorar la fábrica de } \\
\text { parroquias }\end{array}$ \\
\hline $\begin{array}{l}\text { Establecer un tribunal } \\
\text { que decida los pleitos } \\
\text { de los litigantes }\end{array}$ & $\begin{array}{l}\text { Regular la organización de } \\
\text { gremios }\end{array}$ & & \\
\hline
\end{tabular}

\footnotetext{
${ }^{26}$ AGN, Historia 417, fojas 179-182, Instrucciones que la ciudad de Arizpe, capital de las Provincias de Sonora y Sinaloa remiten al Exmo. Sr. d. Miguel de Lardizábal y Uribe, vocal de la América Septentrional de la Suprema Junta Gubernativa de España e Indias].

27 Instrucciones de la provincia de Puebla, 30 de mayo de 1810, en ROJAS, Beatriz. Documentos para el estudio de la cultura política de la transición... Op. cit., pp. 262-273. En 1814 el entonces diputado por esta provincia, Antonio Joaquín Pérez, amplió estas instrucciones, AGI, Indiferente 1354, Exposiciones que hacen los diputados de las provincias sobre las instrucciones que habían recibido de los ayuntamientos para discutir en Cortes.

${ }^{28}$ Instrucción de la provincia de Nuevo León, 20 de julio de 1810, en ROJAS, Beatriz. Documentos para el estudio de la cultura política de la transición... Op. cit., pp. 274-317.

${ }^{29}$ Ibídem, pp. 318-328.
} 


\begin{tabular}{|l|l|l|l|}
\hline $\begin{array}{l}\text { Crear una pensión } \\
\text { que deben admitir los } \\
\text { pueblos para la } \\
\text { administración de } \\
\text { justicia }\end{array}$ & $\begin{array}{l}\text { Repartir tierras; que se regule } \\
\text { sobre montes, pastos y cortes } \\
\text { de madera y leña, y facilitar el } \\
\text { establecimiento de un Ley } \\
\text { Agraria }\end{array}$ & & \\
\hline $\begin{array}{l}\text { Establecer dos } \\
\text { compañías militares } \\
\text { más en Sonora }\end{array}$ & $\begin{array}{l}\text { Restablecer el cultivo y } \\
\text { comercio de la grana }\end{array}$ & & \\
\hline $\begin{array}{l}\text { Que se respeten las } \\
\text { ordenanzas de } \\
\text { minería }\end{array}$ & Suprimir las aduanas interiores & & \\
\hline $\begin{array}{l}\text { Establecer el quinto y y } \\
\text { ensaye a falta de la } \\
\text { Casa de Moneda }\end{array}$ & Valorar la supresión del tributo & & \\
\hline & $\begin{array}{l}\text { Promover la creación de una } \\
\text { Sociedad Económica de } \\
\text { Amigos del País }\end{array}$ & & \\
\hline & $\begin{array}{l}\text { Revisar las leyes y que los } \\
\text { empleos para América se } \\
\text { alternen entre peninsulares y } \\
\text { americanos }\end{array}$ & & \\
\hline
\end{tabular}

Cuadro 2: Instrucciones de provincias de Nueva España elaboradas en $1810^{30}$. Fuente: AGN, Historia 417.

Aunque algunas provincias sólo se pronunciaron para agradecer que las instituciones de la península hubiesen declarado la igualdad de los territorios de la monarquía y, poco más, en su gran mayoría las Instrucciones reflejan las problemáticas de cada una de ellas y la manera que consideraban más adecuada para atenderlas. Estas fuentes nos permiten conocer la situación en que se encontraban hacia inicios del siglo XIX, porque casi todas ellas presentaron una especie de diagnóstico en cada tema que abordaron; casi siempre señalaban que se encontraban en un estado lastimoso, pero que contaba con las condiciones necesarias para lograr una gran prosperidad. Es por ello que también hacían un recuento de aspectos favorables, como la riqueza de la tierra para sembrar diversos productos, un clima benéfico, rutas para el comercio, condiciones adecuadas para establecer fábricas, suficientes habitantes para trabajar en ellas, etc., para señalar que sólo necesitaban los beneficios que se les pudieran otorgar, y fincaban sus expectativas en una buena representación, es decir, en sus diputados.

Pero debemos tener presente que, salvo algunas excepciones, las Instrucciones son documentos elaborados por los ayuntamientos capitalinos, por lo que en gran medida son un reflejo de sus aspiraciones y su deseo de fortalecer y ampliar su zona de influencia, como se muestra de manera clara en el caso de San Luis Potosí. Dicho de otra manera, estas Instrucciones muestran que el ayuntamiento de la ciudad de San Luis Potosí, como seguramente lo hicieron otros, trató de aprovechar la coyuntura política para erigirse como la institución que encabezaría y dirigiría la prosperidad de la provincia. En ellas se observa un claro propósito de hacer coincidir

${ }^{30}$ Valladolid también presentó sus instrucciones este año, pero se adhirió a lo que presentó Guanajuato el año anterior. Por otra parte, la riqueza de la información de las Instrucciones permitiría hacer un análisis comparativo; esto permitiría tener una lectura regional más completa entre 1809 y $1810^{\star * * *}$ 
límites político-administrativos de una provincia que, siendo sede de la intendencia más extensa de la Nueva España, tenía poca vinculación con las demás provincias que la integraban, además de que ella misma obedecía a diferentes jurisdicciones en los ámbitos eclesiástico y de justicia ${ }^{31}$.

Las aspiraciones de San Luis Potosí se plasman en tres documentos cuya riqueza es indiscutible para analizar este tema: las Instrucciones de 1809 -que son las más extensas-, las Adiciones de 1812, y las Instrucciones de 1820. Si bien todas surgieron a raíz de las concesiones que hicieron a los americanos las instituciones que actuaban en nombre del rey, cada una de ellas se elaboró en un contexto singular. Las primeras se elaboraron cuando los ojos estaban puestos en las nuevas prácticas políticas, y fue cuando se generaron mayores expectativas: era la primera vez que tenían la posibilidad de contar un representante en la península dotados de amplios poderes e instrucciones. Las segundas se presentaron luego de dos años de una intensa guerra que había cambiado las dinámicas locales; como resulta lógico, en esos momentos el aumento del poder militar sobre el poder político era más que evidente, lo que llevó a que las instituciones políticas locales intentaran recobrar su influencia, y esto se plasma en las Adiciones de $1812^{32}$. Las Instrucciones de 1820 se elaboraron tras la reinstalación del constitucionalismo, cuando se habían producido cambios significativos en diversos ámbitos luego de 10 años de guerra, lo que implicaba nuevas necesidades; además de que quienes elaboraron las Instrucciones de ese año se nutrían de la experiencia política que se había adquirido desde $1809^{33}$. Las primeras fueron base para las otras dos, y constan de los 12 puntos que se enuncian en el Cuadro 1.

¿Cómo acercarse a estos documentos? Un primer paso es saber cómo y en qué contexto fueron elaborados. Sobre esto último ya hemos hablado, por lo que nos enfocaremos en el primer punto. Al respecto, debemos señalar que tenemos la suerte de contar con fuentes que nos permiten hacer esa reconstrucción, algo que ya hemos realizado de manera puntual en otro trabajo. ${ }^{34}$ Aquí sólo mencionaremos que en 1809 el ayuntamiento comisionó a dos regidores para llevar a cabo tan importante tarea, Francisco Justo García y Juan Mariano Vildósola, quienes, mediante un oficio que presentaron a nombre del ayuntamiento, pidieron su opinión a varios individuos residentes en la ciudad sobre una propuesta que ya habían

\footnotetext{
${ }^{31}$ La intendencia de San Luis Potosí comprendía las provincias de Nuevo Reino de León. Nuevo Santander, Coahuila y Texas. Creada en 1786 por medio de la Real Ordenanza de Intendentes de Nueva España, no había logrado la integración esperada, y los conflictos con los gobernadores de las demás provincias fue la constante. A esto se debe considera que, eclesiásticamente, la provincia de San Luis Potosí estaba sujeta a las mitras de México, Valladolid, Nueva Galicia y Linares, mientras que, en materia de justicia, una parte estaba sujeta a la Audiencia de México, y otra a la de Nueva Galicia.

${ }^{32}$ AHESLP, Ayuntamiento de San Luis Potosí, Actas de cabildo, 19 de abril de 1812, Adiciones a las Instrucciones que presenta el ayuntamiento de San Luis Potosí para sus diputados a Cortes.

33 AHESLP, Ayuntamiento de San Luis Potosí, Actas de cabildo, 17 de noviembre de 1820, Instrucciones que proponen los procuradores Pedro Fernández y Cayetano Díaz Bracamonte, para extender las que hayan de darse a los señores Diputados en Cortes por la Provincia de San Luis Potosí.

${ }^{34}$ Para un análisis puntual de los tres documentos y de su elaboración véase BERNAL RUIZ, Graciela. Sin quedarle qué envidiar a la metrópoli de México... Op. cit.
} 
elaborado, en la que planteaban los temas que, a su parecer, debían tratarse en las Instrucciones.

Con ese documento como base, además de pedir su opinión, debían señalar cuanto les pareciera conveniente incluir en ellas para que esta ciudad y su provincia lograran la prosperidad deseada, pero que al mismo tiempo contribuyera al mejoramiento del conjunto del reino, y de los "justos intereses" del monarca ${ }^{35}$. Más relevante aún es que, a decir de uno de los individuos consultados, los comisionados pedían que opinaran sobre todos los ámbitos del gobierno: sobre leyes que reformaran el código civil, criminal y mercantil; reflexiones sobre la economía y arreglo a los ramos de Real Hacienda y su recaudación; sobre establecimientos útiles, poblaciones, comercio, agricultura, repartimiento de tierras y demás materias de gobierno. En definitiva, que opinaran sobre la manera de desterrar vicios de la administración para que la América llegara "al más alto punto de opulencia, prosperidad y felicidad general y particular" ${ }^{36}$.

Los 15 individuos consultados recibieron el oficio a finales de abril de $1809 \mathrm{y}$ enviaron sus respuestas entre mayo y julio; se consultó a ministros, mineros, hacendados, curas y priores de conventos. Estas respuestas son documentos de indiscutible valor porque muestran una variedad de intereses y el estado en que se encontraban la ciudad y provincia de San Luis Potosí en 1809, información que abona al conocimiento de los deseos de autonomía que envolvía a los grupos de poder local, la manera como visualizaban a la provincia, así como de las personas que consideran idóneas para estar el frente de su administración y gobierno.

La extensión de las respuestas es variada, así como también los temas que abordaron. Algunos mencionaban las pocas luces con que contaban para opinar sobre temas tan importantes, mientras que otros enviaron amplios documentos que nos hablan de un conocimiento profundo de la jurisdicción, pero también dejaron ver sus intereses particulares. Estos últimos se omitieron en las Instrucciones que se enviaron a la península y se privilegiaron aspectos que pudieran resultar de mayor interés para la provincia en su conjunto y que, a su vez, reflejara un beneficio para la monarquía, como se mostrará más adelante. El documento final incluye partes íntegras de algunas de esas respuestas, sobre todo del tesorero de las Reales cajas Cristóbal Corbalán y del ministro contador Josep Caballero Basave. Suponemos que los comisionados elaboraron las Instrucciones a partir de todas las respuestas y las presentaron en sesión de cabildo para su aprobación -la documentación no indica cómo se integraron las propuestas-. Como se ha señalado anteriormente, las Instrucciones están fechadas el 24 de octubre de 1809, casi tres meses después de haber recibido las últimas respuestas.

El siguiente paso es identificar la estructura de las Instrucciones. Éstas cuentan

\footnotetext{
${ }^{35}$ AHESLP, Ayuntamiento de San Luis Potosí, Actas de cabildo, 16 de junio de 1809, Propuesta que presenta José Estanislao Esnaurrizar al ayuntamiento de San Luis Potosí para elaborar las instrucciones.

${ }^{36}$ AHESLP, Ayuntamiento de San Luis Potosí, Actas de cabildo, 19 de junio de 1809, Respuesta que presenta Joseph Caballero Basave al ayuntamiento de San Luis Potosí para elaborar las instrucciones.
} 
con un preámbulo en donde agradecen a la Junta Central que, en medio de los asuntos graves y urgentes del momento, tuviese presente la importancia de trabajar por el fomento de las provincias, pues esto contribuiría "a la felicidad de la Nación". Asimismo, se señalaba, sin entrar en detalles, que para elaborar las Instrucciones se había tomado la opinión de diversos individuos de "experiencia y letras", por lo que se había convenido "con uniformidad en la necesidad de los establecimientos que se han pretendido y se solicitan ahora por este cuerpo". Consideramos que con esta enunciación intentaban dotar a las Instrucciones de mayor legitimidad.

En el preámbulo también encontramos un reconocimiento a las instituciones que actuaban en nombre del rey y a las concesiones que se habían otorgado a los americanos; al hacerlo, se observa una clara apropiación del lenguaje político del momento: la representación, los principios de equidad y justicia, y la nueva constitución del reino. Después señalaban la importancia de diseñar e implementar las reformas que exigían las nuevas circunstancias, a las que por supuesto el ayuntamiento de San Luis Potosí deseaba contribuir.

Posteriormente, se presentan numerados los temas que se consideran necesarios para la prosperidad de la provincia. En cada uno de ellos se hace un diagnóstico que permite conocer, si no el origen del asunto a tratar, al menos un poco de historia, y el estado en el que se encontraba en esos momentos, para posteriormente hacer la petición específica, seguida de los beneficios que se obtendrían; esto se observa también en las Instrucciones de otras provincias. Esto último era un punto fundamental para que se atendieran las peticiones, por lo que se cuidaron de señalar los beneficios que recibiría la provincia, pero también el conjunto de la monarquía; se aseguraba que, si se atendían las peticiones, esto derivaría en el ahorro de recursos, en el aumento de la recaudación, en la tranquilidad pública, en la instrucción, etc., y que todo ello ayudaría a reforzar la lealtad al monarca, exaltando aún más la bondad que, decían, le caracterizaba. Además, es importante señalar que más que hacer una crítica puntual a las leyes vigentes -que sí la hacían, insistían en que debía nombrarse a los individuos más adecuados para estar al frente del gobierno en América y, como era de esperarse, pedían mayor participación de los americanos, pero siempre en un tono conciliador y buscando un equilibrio o alternancia en los cargos.

Aquí retomamos los 12 puntos que aparecen el Cuadro 1:

1. Creación de un obispado con sede en la ciudad de San Luis Potosí.

2. Establecimiento de una fábrica de puros y cigarros.

3. Habilitación de un puerto en Soto la Marina.

4. Repartimiento de tierras y venta de ellas en enfiteusis.

5. Permiso para los subdelegados realizaran el repartimiento de mercancías.

6. Establecimiento de una fábrica de efectos con materias primas.

7. Reformar el real derecho de pulperías.

8. Suprimir los tributos de indios, mulatos y castas.

9. Reformar el honorario de administradores y receptores de alcabalas.

10. Reconocer los méritos y servicios de los empleados americanos. 
11. Nombramiento de intendente, pues el titular del cargo estaba imposibilitado por motivos de salud.

12. Celebración de un Concilio nacional.

¿Qué nos permiten observar estas peticiones? Un primer paso para saber el plan general del ayuntamiento de San Luis Potosí es identificar qué se pretendía con cada una de ellas, para después encontrar su vinculación con los aspectos que podían garantizar una autonomía y cómo se materializaba: por ejemplo, convertirse en un centro económico que articulara una amplia región con influencia hacia otras regiones económicamente importantes, dejar de depender de la capital del virreinato en ciertos aspectos -como el abasto de puros y cigarros-, así como del puerto de Veracruz o de las mitras a las que estaba sujeta la provincia y, en ese sentido, hacer coincidir límites político-administrativos y fortalecer a la provincia en términos económicos. Pero vayamos por partes. 


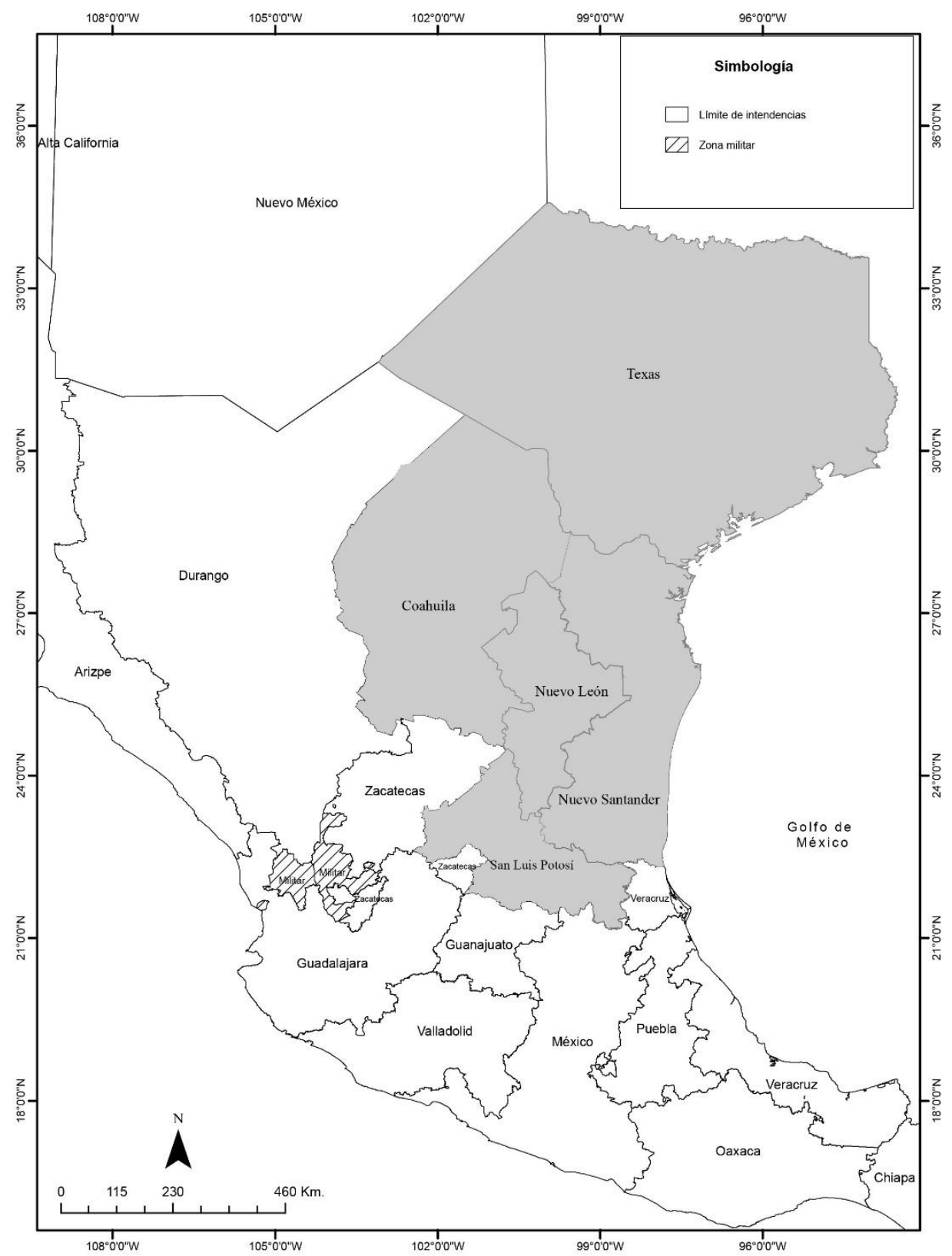

Mapa 1: Intendencia de San Luis Potosí. Fuente: José Luis Alcauter Guzmán.

El obispado se consideraba de vital importancia porque las subdelegaciones de la provincia caían dentro de los límites de varias mitras: México, Valladolid, Nueva Galicia y Linares. En las Instrucciones se detallan los límites propuestos para la mitra que buscaban establecer en San Luis Potosí, y éstos coinciden en gran medida con los de la provincia, sólo se agregaban cuatro curatos que pertenecían a Guanajuato y Zacatecas. Los argumentos para solicitar el obispado era el abandono en que se encontraban por parte de los prelados, aunque por supuesto estaba la recaudación del diezmo que, aunque se presentaba como un segundo punto de importancia, era uno de los temas que más interesaba al ayuntamiento: la cantidad recaudada por 
diezmo en esta provincia iba a parar a las arcas de otras jurisdicciones. Respecto a la fábrica de puros y cigarros, aseguraban que su establecimiento terminaría con los problemas de ociosidad que preocupaban a las autoridades porque daría ocupación a hombres y mujeres, y aseguraban tener las condiciones para su establecimiento, además de contar con una posición geográfica adecuada para distribuir el producto a lugares alejados del norte, concretamente a las demás provincias de la intendencia.

La habilitación del puerto Soto la Marina les permitiría tener una salida directa al mar para comerciar sus productos fuera de la Nueva España, y para la introducción directa de mercancías que seguramente pretendían distribuir a diversas zonas dentro y fuera de la provincia; en este sentido, dejarían de depender del puerto de Veracruz, además de la ciudad de México, desde donde también se distribuían los productos que llegaban San Luis Potosí y el resto de la intendencia. El puerto solicitado no estaba en los límites de la provincia -San Luis Potosí no tenía salida al mar-, pero sí de la intendencia, en Nuevo Santander, y para mostrar los beneficios que se obtendrían con su habilitación, presentaron información sobre el ahorro que significaría en distancias recorridas y costo de los viajes. Por otra parte, aseguraban que la habilitación de este puerto ayudaría a disminuir el comercio ilícito que se practicaba en el Seno Mexicano y los territorios del norte del virreinato.

Para contribuir al fomento, señalaban que resultaba de suma importancia el repartimiento de tierras o su venta en enfiteusis, sobre todo a españoles pobres, mulatos libres y demás castas que no contaban con ellas; inicialmente la propuesta consideraba tierras realengas, aunque al no existir este tipo de tierras en la provincia, se recurriría a las haciendas, con el claro objetivo de poner a producir las tierras que sus dueños no alcanzaran a sembrar, o aumentar la producción de aquellas que eran arrendadas, pues quienes las recibirían seguramente pondrían mayor empeño en aumentar sus cosechas. Por otra parte, pedían la restitución de los repartimientos con la firme convicción de que esto ayudaría a regular los precios de los productos, aunque conscientes de los perjuicios que representaban para los indios, sólo proponían una mayor regulación, imponiendo castigos a los abusos que pudieran cometerse por parte de los recaudadores.

Respecto al establecimiento de fábrica de efectos de la tierra, tenían presente ciertas prohibiciones en esta materia, por lo que solicitaban la libre fabricación sólo de prendas de "algodón y lana para paños ordinarios; pañetes, bayetas, sayales, mantas de algodón de todas clases y todo género de rebozos que usan las mujeres y no vienen de España", pero también de lencería de lino y cáñamo, asegurando que la venta de sus productos sería el medio más adecuado para fomentar la industria local. Por otra parte, aseguraban que el real derecho de pulperías implicaba una pesada carga para los dueños de estos establecimientos -en donde se vendían algunas de las prendas mencionadas anteriormente-, por lo que pedía disminuir el monto de la contribución, y que, para establecer esa cantidad, dejara de considerarse el rango que tenían las ciudades, porque la contribución era más alta en las capitales de intendencia, pero esta categoría no reflejaba necesariamente su riqueza. Aunque, de ser posible, pedían la eliminación de esta contribución. 
Para abordar la supresión del tributo señalaban que éste era la carga que más afligía y aniquilaba a los indios y castas, y que el nombre de tributarios les imprimía una señal negativa, además de que sufrían muchas vejaciones por parte de quienes realizaban el cobro. Agregaban que todos los tributarios querían "ser libres y reputados por españoles como ellos lo son en realidad". Para compensar el monto que se dejaría de recaudar si se suprimía el tributo, se proponía que los indios pagaran alcabala, algo de lo que estaban exceptuados. Sobre esta contribución, además de incluir a los indios, pedían sustituir las percepciones de los recaudadores, que hasta ese momento recibían el 14\% de todo lo recaudado, por un plan de sueldos, porque con ello también se evitarían los abusos cometidos por quienes deseaban aumentar sus ingresos a partir del monto recaudado.

En el noveno punto pedían el reconocimiento de los méritos y servicios a los americanos para que éstos fuesen tomados en cuenta para ocupar cargos en América y en la península; para ello planteaban que debía tomarse en cuenta la experiencia que tuvieran en las áreas que administrarían y los méritos que hubiesen obtenido; aseguraban que esto contribuiría a eliminar las rivalidades existentes entre los individuos de origen peninsular y americano. Por otra parte, la petición de que se nombrara a un intendente obedecía a que desde 1805 actuaba de manera interina en este cargo el teniente letrado, por enfermedad del titular, por lo que esta petición era para atender un problema de ese momento, aunque esperaban el nombramiento de un individuo afín a los intereses locales. Finalmente, con la realización de un Concilio Nacional pretendían atender el problema de la relajación de las costumbres -empezando por el clero-; aseguraban que, al ser la base en que se cimentaba la sociedad, un plan efectivo para mejorar las costumbres debería tener como centro a la religión.

Como se puede apreciar, las 12 peticiones planteadas en ese orden ya enuncian varios puntos de intersección, 0 , dicho de otra manera, pueden considerarse complementarias, lo cual resulta lógico teniendo en cuenta que se buscaba el fomento de la provincia y esto requería no sólo implementar varias acciones, sino pensar en su operatividad, lo que implicaba un ajuste de disposiciones, que en este caso se relacionaban con la recaudación o la creación de nuevas instituciones. Indudablemente los límites administrativos era un tema crucial y esto se plasma de manera más clara en la solicitud del obispado, y también se muestra de manera explícita al señalar que éste era el punto de mayor importancia para la provincia. Los argumentos utilizados eran fundamentales, por lo que hicieron una recapitulación de los inconvenientes que implicaba para los habitantes de la provincia pertenecer a varias mitras, centrándose en la dificultad del traslado a la sede de los obispados a los que estaban sujetos y la poca atención que recibían por parte de los prelados. Al referirse a los diezmos, enfatizaban en que recibían pocos beneficios y que, si se establecía la mitra en San Luis Potosí, esto redundaría en beneficios para la fábrica espiritual, además de que los feligreses tendrían una atención más efectiva por parte del clero. Se aspiraba a que la capital de la intendencia más extensa de la Nueva España fuese sede de un obispado, privilegio que sólo tenían algunas provincias.

En cuanto a la figura de gobierno, si bien otras provincias pedían la supresión de 
las intendencias, el ayuntamiento de San Luis, que había tenido importantes diferencias con quienes habían ocupado ese cargo, no consideraba esta opción, porque valoraba las ventajas que les otorgaba el ser capital de intendencia. Sus esfuerzos se enfocaban en que se nombrara intendente a una persona afín a los intereses locales, y aunque en las Instrucciones no lo dicen de manera clara, no faltó quien considerara al comandante militar de la Décima Brigada -Félix María Callejapara que fuera favorecido con este nombramiento.

Sin lugar a duda la prosperidad de la provincia sólo podría lograrse atendiendo los aspectos económicos y la recaudación. La mayor parte de los puntos abordados en las Instrucciones se vinculan con estos temas, como se aprecia en la explicación que se realizó de cada uno de ellos, y de manera más clara al vincular la información que arrojan: la ciudad de San Luis Potosí buscaba ser el centro articulador del comercio en los territorios de la intendencia: Nuevo Santander, Nuevo Reino de León, Coahuila y Texas, y tener una influencia en otras regiones, como Zacatecas y Guanajuato. Esto nos parece más evidente cuando abordan el tema del puerto, en donde presenta la siguiente información.

\begin{tabular}{|l|c|c|c|c|c|c|}
\hline \multicolumn{7}{|c|}{ RESUMEN DE LAS VENTAJAS OBTENIDAS DE LA HABILITACIÓN DEL PUERTO SOTO LA } \\
\hline \multicolumn{1}{|c|}{ Destino } & \multicolumn{2}{|c|}{ Leguas desde el origen } & \multicolumn{2}{c|}{$\begin{array}{c}\text { Jornadas desde el } \\
\text { origen }\end{array}$} & \multicolumn{2}{c|}{ Fletes desde el origen } \\
& Veracruz & $\begin{array}{c}\text { Soto la } \\
\text { Marina }\end{array}$ & Veracruz & $\begin{array}{c}\text { Soto la } \\
\text { Marina }\end{array}$ & Veracruz & $\begin{array}{c}\text { Soto la } \\
\text { Marina }\end{array}$ \\
\hline Al Saltillo & 300 & 123 & 60 días & 25 días & 33 pesos & 8 pesos \\
\hline $\begin{array}{l}\text { Al Real de } \\
\text { Catorce }\end{array}$ & 250 & 96 & 50 días & 19 días & 27 pesos & 7 pesos \\
\hline A Zacatecas & 250 & 154 & 50 días & 31 días & 27 pesos & 10 pesos \\
\hline A Guanajuato & 180 & 160 & 36 días & 32 días & 21 pesos & 10 pesos \\
\hline A SLP & 200 & 116 & 40 días & 23 días & $\begin{array}{c}22 \text { pesos } \\
4 r\end{array}$ & 8 pesos \\
\hline
\end{tabular}

Cuadro 3: Resumen de las ventajas obtenidas de la habilitación del puerto Soto la Marina. Fuente: AHESLP, Ayuntamiento, Actas de Cabildo, 24 de octubre de 1809... ${ }^{37}$

Lo anterior refleja un plan para la implementación de un comercio a nivel regional con puntos estratégicos para su distribución, ya sea por el área que podría abarcar (Saltillo como punto de contacto hacia el norte), o porque significaban un importante mercado de venta: los reales mineros concentraban población numerosa que demandaba productos de diversa índole, además de los que resultaban necesarios para la actividad minera. Esto se complementaba con la intención de consolidar la colonización del norte de la intendencia, que contaba con escasa densidad de población. Por otra parte, el repartimiento seguramente se consideraba para incentivar el comercio local.

Sin duda, esta red de comunicación favorecería la distribución de lo que se produciría en la provincia con las fábricas de cigarros y de efectos de la tierra, las

37 AHESLP, Ayuntamiento, Actas de Cabildo, 24 de octubre de 1809, Instrucción que, en cumplimiento de la Real Orden de 22 de enero del presente año de 1809 librada por la Suprema Junta Central depositaria de la autoridad Soberana, el ayuntamiento de SLP envía al Exmo. Sr. D. Miguel de Lardizábal, diputado representante por la Nueva España y vocal de dicha Suprema Junta. 
que, a su vez, se abastecerían en parte con la producción que se esperaba aumentar al repartir las tierras e implementar diversos cultivos, entre ellos, por supuesto el tabaco, el cáñamo. Para favorecer el comercio también se contemplaba la reforma de la alcabala, que ahora debían pagar los indios, y para hacerlo posible no dudaron en retomar los postulados liberales: ahora todos eran iguales, por lo tanto, todos debían contribuir de la misma manera. Este proyecto contemplaba un plan de sueldos: para los recaudadores de alcabalas, para los funcionarios de la fábrica de puros y cigarros, y para los subdelegados.

Lo que nos muestran las Instrucciones, es que los grupos de poder local como los de San Luis Potosí, lograron articular en un documento las aspiraciones políticas y económicas que ya tenían, con los nuevos tiempos políticos que se presentaban, en los que se planteaba una nueva manera de vincularse con la monarquía. Ya lo decía de manera clara la Regencia del Reino en su decreto de 14 de febrero de 1810:

"Españoles Americanos, os véis elevados a la dignidad de hombres libres [...] vuestros destinos ya no dependen ni de los ministros, ni de los Virreyes, ni de los Gobernadores; están en vuestras manos"38.

Sin embargo, un poco de retrospectiva nos permite mostrar que, si bien éste era el momento más propicio para hacer las solicitudes, como señaló uno de los individuos consultados por el ayuntamiento de San Luis Potosí ${ }^{39}$, algunas de las peticiones contempladas en las Instrucciones no eran nuevas. Hace tiempo Carmagnani señalaba que, al menos desde el siglo XVIII diferentes grupos de poder a nivel local y provincial habían encontrado mecanismos de acción que evitaran el desorden en los diferentes ámbitos del gobierno y sus finanzas, y esto los había llevado a cierta "autodeterminación" ${ }^{40}$. En años más recientes, Portillo también ha identificado elementos autonomistas desde el siglo XVIII en las provincias americanas $^{41}$. Para ello debieron implementar diversas negociaciones que no estuvieron exentas de conflictos, pero les permitieron ganar algunas batallas, y cuando se presentó la crisis monárquica estaban intentando librar otras tantas.

En el caso de San Luis Potosí el ejercicio de retrospectiva lo marcan algunos de los temas que trataron en las propias Instrucciones, porque al contextualizarlos proporcionan pistas que permiten imaginar una reflexión de larga o mediana duración de esos temas por parte de los actores locales. Una búsqueda y revisión de documentos de la intendencia, de las actas de cabildo y de protocolos notariales de

\footnotetext{
${ }^{38}$ AGN, Bandos, vol. 25, exp. 80, 14 de febrero de 1810, El Consejo de Regencia de España e Indias a los americanos españoles.

${ }^{39}$ AHESLP, Ayuntamiento de San Luis Potosí, Actas de cabildo, Propuesta que presentan Ignacio de Astegui y Pedro Manuel de Castro, a nombre del Noble y Leal Gremio de la Minería, al ayuntamiento de San Luis Potosí para elaborar las instrucciones. La fecha en que fue presentada es ilegible.

${ }^{40}$ CARMAGNANI, Marcelo. Territorios, provincias y estados: Las transformaciones de los espacios políticos en México, 1750-1850. En: VÁZQUEZ, Josefina. La fundación del Estado Mexicano. Nueva Imagen, 1994, p. 29.

${ }^{41}$ PORTILLO, José María. Crisis Atlántica. Autonomía e Independencia en la crisis de la monarquía hispana. Madrid: Marcial Pons; Fundación Carolina, 2006.
} 
las últimas décadas del siglo XVIII corroboran esta hipótesis.

\section{Hacer un poco de memoria}

Las coyunturas siempre generan una amplia documentación por los efectos que tienen en diferentes ámbitos, algo que favorece la labor de investigación, porque además no es raro que en ella se haga un recuento de eventos previos a los cambios que se estén generando. Si buscamos una coyuntura que despertó con mayor ahínco las aspiraciones de los grupos de poder local antes de la que se presentó en 1809 esa es el establecimiento del sistema de intendencias. El impacto que esto tuvo en las dinámicas locales sólo es posible entenderlo si se considera que se trató de una reestructuración territorial y administrativa que creó poderes regionales, justamente las intendencias, que articularían en 12 jurisdicciones la gran cantidad de alcaldías mayores y corregimientos existentes en ese momento. Como podrá suponerse, esto afectó a los grupos de poder local, no sólo por esa reestructuración que en algunos temas obligó a una rearticulación de vínculos, sino porque, además, el establecimiento de intendencias trajo consigo el nombramiento de un nuevo funcionario que vigilaría de manera más cercana aspectos tan importantes como la recaudación, y porque también se ajustarían las competencias de las autoridades locales ${ }^{42}$. Todo ello generaría numerosos conflictos entre las diversas autoridades y en algunos casos obligaría a la negociación.

La implementación de la nueva administración y los conflictos que casi de inmediato se suscitaron en San Luis Potosí, quedaron registrados en la documentación de la intendencia y en las actas de cabildo, que en su mayor parte resguarda el Archivo Histórico del Estado de San Luis Potosí. Algunos otros documentos se encuentran en diversos ramos del Archivo General de la Nación, sobre todo en los ramos de Intendencias y Ayuntamientos, pero también en los que contienen información de propios y arbitrios, tierras, tributos, bandos, reales cédulas, etc. Otros más se resguardan en el Archivo General de Indias. Pero la base para conocer las aspiraciones locales, sin lugar a duda, es la documentación que se localiza en el primer archivo.

Las actas de cabildo registran las resistencias de esta institución para atender las nuevas disposiciones, principalmente cuando el intendente solicitaba las cuentas de propios y arbitrios; asimismo, permiten hacer un seguimiento de la discusión sobre diversos temas que afectaban sus competencias. Por su parte, los documentos de la intendencia muestran la manera como su titular, intentando cumplir con sus atribuciones y obligaciones, no cesó en solicitar que se cumplieran las disposiciones de la Real Ordenanza, y que, ante la negativa del cabildo, pedía la intervención del virrey. Una dinámica similar se presentó con otros temas.

\footnotetext{
${ }^{42}$ Esto proceso ha sido analizado por una diversidad de autores, entre los que destaca el trabajo de PIETSCHMANN, Horst. Las Reformas Borbónicas y el sistema de Intendencias en Nueva España. Un estudio político administrativo. México: FCE, 1996; por otra parte, el proceso ha sido caracterizado por Carlos Garriga como el proceso de administrativización", GARRIGA, Carlos. Gobierno y justicia: El gobierno de la justicia. En: La jurisdicción contencioso administrativa en España. Una historia de sus orígenes. VII. Madrid: Consejo General del Poder Judicial, 2008, p. 50.
} 
En ese contexto, las actas de cabildo resguardan algunas peticiones que los integrantes del cabildo hicieron a la Corona aprovechando la calidad que ahora tenía la ciudad como capital de intendencia: un obispado ${ }^{43}$ y una fábrica de puros y cigarros $^{44}$. Aunado a esto, se observan estrategias para fortalecer a la corporación con el constante remate de cargos que se encontraban vacantes; esto dio como resultado que a inicios del siglo XIX el ayuntamiento se hubiese convertido en una institución fuerte que pudo adaptarse mejor a las nuevas circunstancias.

A su vez, en otras fuentes encontramos reflexiones puntuales sobre dos puntos más que aparecieron en las Instrucciones, que aun cuando no surgieron del ayuntamiento, resulta claro que terminaron por apropiárselos: un puerto ${ }^{45}$, y la propuesta para la venta de tierras en enfiteusis ${ }^{46}$. Por otra parte, la provincia, a través de su intendente, participó de la discusión sobre la pertinencia de reestablecer el repartimiento de mercancías, que se había suprimido con el establecimiento de las Intendencias ${ }^{47}$.

La solicitud más antigua era el obispado, la primera que se ha identificado es de 1776, en un contexto en el que se estaban atendiendo las propuestas para crear obispados en Arizpe y Linares; estos dos fueron aprobados, pero no la de San Luis Potosí. Se volvió a solicitar en 1792 y en 1801, este último proceso se extendió por varios años, y se hizo a través de un procurador de Madrid que también estaba atendiendo la solicitud de obispado presentada por Veracruz ${ }^{48}$. El primer punto de las Instrucciones reproduce casi de manera íntegra el texto que se redactó para estas peticiones. mientras que la fábrica de puros y cigarros fue solicitada en 1790 , aprovechando, decían, el prestigio que les brindaba ser capital de intendencia. El documento que en ese momento elaboraron es prácticamente el mismo texto que aparece en el punto 2 de las Instrucciones.

\footnotetext{
${ }^{43}$ AHESLP, Ayuntamiento de San Luis Potosí, Actas de cabildo, 17 de marzo de1804, Argumentos para solicitar la erección de obispados en la ciudad de San Luis Potosí, Valles, Valle del Maíz y Pánuco. En este expediente se menciona la petición de 1776 y se recapitula la de 1792.

${ }^{44}$ AHESLP, Ayuntamiento de San Luis Potosí, Actas de cabildo, 1790, Solicitud del establecimiento de una fábrica de cigarros en la ciudad de San Luis Potosí. Los documentos relativos a este caso se encuentran entre enero y julio del año mencionado.

${ }^{45} \mathrm{AGI}$, México 1445, Informe del coronel Félix Calleja sobre la Colonia del Nuevo Santander, 1795.

${ }^{46}$ AGN, Tierras, vol. 3129, cuaderno 7, Sobre libertar de inundaciones al Valle de San Francisco y repartimientos de tierras para propagar la agricultura, 1791.

${ }^{47}$ AGN, Subdelegados, vol. 35, exp. 11, Respuesta del intendente de San Luis Potosí a la circular del virrey de 22 de agosto de 1792 sobre la práctica del repartimiento en su jurisdicción antes del establecimiento del régimen de intendencias.

${ }^{48}$ Llama la atención la constante negativa de las autoridades para autorizar la creación del obispado de San Luis Potosí. En 1776 resulta claro que se debió a la importancia de las nuevas mitras (Arizpe y Linares), porque se plantearon en el marco de un amplio proyecto para ejercer un control más efectivo del norte del virreinato, que también contempló la creación de la Comandancia de las Provincias Internas. En las demás solicitudes, al menos las que se presentaron antes del inicio de la guerra, hubo una fuerte oposición del obispado de Valladolid de Michoacán, a cuya mitra estaba sujeta la ciudad de San Luis Potosí. Véase BERNAL RUIZ, Graciela. Sin quedarle qué envidiar a la metrópoli de México... Op. cit, pp. 141-148.
} 
Respecto al puerto, como decíamos, no hay una solicitud del ayuntamiento, sino de Félix María Calleja; en el informe que presentó cuando fue comisionado para arreglar las Compañías militares del Nuevo Santander planteaba la conveniencia de habilitar dos puertos, Soto la Marina y Tampico, y las ventajas que señaló fueron retomadas por el ayuntamiento en sus Instrucciones de 1809, cuando solicitó la habilitación de Soto la Marina, mientras que Tampico fue incluido en las adiciones que presentaron en $1812^{49}$. En cuanto al repartimiento de tierras, fue el intendente quien habló del tema a inicios de 1791, luego de realizar la visita a las poblaciones cercanas a la intendencia, cuando señalaba la importancia de poner a trabajar una mayor cantidad de tierras y de repartirlas entre arrendatarios. Si bien en ese momento le generó un fuerte conflicto con los hacendados, es significativo que parte de esta propuesta nutriera el punto 4 de las Instrucciones.

El tema del repartimiento fue uno de los más debatidos desde que en la Real Ordenanza de Intendentes se declarara su supresión. El virrey no tardó en pedir su opinión a los diferentes intendentes, muchos de los cuales se pronunciaron por su restablecimiento, entre ellos el de San Luis Potosí, y todo apunta a que era uno de los pocos temas en los que coincidía con el ayuntamiento; el argumento -que prácticamente era generalizado entre quienes opinaron al respecto-, era que esto ayudaría a agilizar el comercio local. En este punto también se opinaba sobre las percepciones de los subdelegados, y se planteaba la propuesta de establecer un plan de sueldos, como después fue retomado por el ayuntamiento al tratar el tema de las alcabalas.

Lo anterior muestra que algunos de los puntos más importantes de las Instrucciones de 1809 ya habían sido solicitados o reflexionados de manera amplia desde la última década del siglo XVIII; en estricto sentido, nos referimos a los primeros cinco puntos que se plantearon en ellas, así como algún aspecto relacionado con el punto nueve (las alcabalas). Por otra parte, el reconocimiento de los méritos y servicios de los empleados americanos fue una demanda constante prácticamente en toda la América hispana durante el siglo XVIII, y quizá con mayor intensidad desde el establecimiento de las intendencias. Finalmente, no podemos dejar de mencionar que en 1799 el entonces juez de testamentos, capellanías y obras pías del obispado de Valladolid, Manuel Abad y Queipo, en su "Representación sobre la inmunidad personal del clero", había planteado la supresión del tributo y el reparto de tierras como una manera de aliviar la situación de un importante sector de la población ${ }^{50}$. Esto resulta significativo porque en ese documento hace una especie de diagnóstico de la situación en que se encontraba la población que comprendía el obispado de Valladolid, al que estaba sujeta la ciudad

\footnotetext{
${ }^{49}$ La primera noticia que tenemos sobre la propuesta para habilitar en puerto en esta zona es la que promovió José de Escandón a mediados del siglo XVIII. TIENDA DE CUERVO, José. Estado general de las fundaciones hechas por $d$. José Escandón en la colonia del Nuevo Santander. Tomo II. México: Talleres gráficos de la Nación, 1929, pp. 378-379

${ }^{50}$ ABAD Y QUEIPO, Manuel. Representación sobre la inmunidad personal del clero, reducida por las leyes del nuevo código, en el cual se propuso al rey el asunto de diferentes leyes que establecidas harían la base principal de un gobierno liberal y benéfico para la América y para su metrópoli. En: ABAD Y QUEIPO, Manuel. Colección de los escritos más importantes que en diferentes épocas dirigió al gobierno d. Manuel Abad y Queipo, obispo electo de Michoacán, México: En la Oficina de Mariano Ontiveros, 1813, pp. 1-65.
} 
de San Luis Potosí, información pudo ser conocida en el ámbito del obispado.

La realización de este ejercicio muestra a la coyuntura de 1808 como una oportunidad para que algunos ayuntamientos, como el de San Luis Potosí, buscaran formalizar y legitimar aspiraciones que venían buscando para consolidar un poder trastocado desde el establecimiento de las intendencias, pero que también intentaron ampliarlo: aspiraban a ejercer el gobierno sobre una entidad bien definida en términos administrativos.

Sin duda los efectos de la guerra iniciada en 1810 obligaron a ajustar las Instrucciones de 1809, algunos puntos tratados en ellas ya no tenían sentido -por ejemplo, el tributo fue abolido por las Cortes y ya se había nombrado a un intendente propietario-, y otros temas cobraban mayor relevancia, como solicitar la habilitación de dos puertos en lugar de uno, y buscar el reconocimiento a las acciones de los habitantes de la ciudad de San Luis Potosí en el combate a los insurgentes. En estas Adiciones, que se encuentran en las actas de cabildo resguardadas por el Archivo Histórico del Estado de San Luis Potosí ${ }^{51}$, también solicitaron el establecimiento de una Junta de Revisión para las causas criminales; con ello no se buscaba la separación de las audiencias de México y Nueva Galicia -a las que estaban sujetas las subdelegaciones de la provincia-, pero sí pretendían crear una instancia en donde se dirimieran algunos asuntos antes de canalizarlos a la respectiva audiencia, y que en cierto sentido, sería una institución intermedia con competencia en toda la provincia. Estas Adiciones mantenían como prioridad el obispado, la fábrica de puros y cigarros, y el puerto que ya mencionamos, al que se agregaba uno más.

Por su parte, las Instrucciones de 1820, también localizas en las Actas de cabildo del Archivo Histórico del Estado de San Luis Potosí ${ }^{52}$, se presentaron en una nueva coyuntura: el restablecimiento de la Constitución de Cádiz que había sido derogada en 1814. Las circunstancias que prevalecían en el virreinato luego de 10 años de guerra y de la experiencia política que se adquirió después de intensos debates en las Cortes entre 1810 y 1814 nuevamente obligaron a ajustar las prioridades. Para redactar las nuevas Instrucciones se comisionó a los procuradores del ayuntamiento Pedro Fernández y Cayetano Díaz Bracamonte. Este documento mantenía la solicitud de obispado, el repartimiento de tierras, los puertos de Soto la Marina y Tampico y la fábrica de cigarros; aunque se agregaban algunos puntos, por ejemplo, que el nombramiento de curas se hiciera mediante ternas en las que se valoraran las cualidades de los candidatos.

Entre los nuevos temas encontramos a la educación -ya reflexionada de manera amplia por uno de los individuos consultados en 1809, pero no se incorporó en las

\footnotetext{
${ }^{51}$ AHESLP, Ayuntamiento de San Luis Potosí, Actas de Cabildo, 19 de abril de 1812, Adiciones a las Instrucciones que presenta el ayuntamiento de San Luis Potosí para sus diputados a Cortes.

52 AHESLP, Ayuntamiento de San Luis Potosí, Actas de cabildo, 17 de noviembre de 1820, Instrucciones que proponen los procuradores Pedro Fernández y Cayetano Díaz Bracamonte, para extender las que hayan de darse a los señores Diputados en Cortes por la Provincia de San Luis Potosí.
} 
Instrucciones de ese año-, al respecto señalaban la importancia de ampliar las escuelas de primeras letras. Asimismo, proponían la creación de hospicios en todas las capitales de provincia cuyos gastos debían ser cubiertos con el diezmo recaudado. Abordaban las contribuciones implementadas por la situación de guerra, ya fuera para establecer montos más "justos" o para pedir la extinción de algunas de ellas. Y ahora sí se cuestionaba la conveniencia de las intendencias, a las que consideraba "ociosas en la actualidad", y se pronunciaban por las Diputaciones provinciales que debería existir en cada provincia, pues en ese momento la de San Luis Potosí estaba unida a Guanajuato ${ }^{53}$. El ayuntamiento veía con recelo que actores políticos de otra provincia decidieran sobre sus asuntos internos.

En definitiva, las Instrucciones son fuentes de indiscutible valor para conocer el estado en que se encontraban las provincias cuando se presentó la crisis de 1808 pero, sobre todo, una buena guía para identificar de manera puntual las aspiraciones de los grupos de poder local, las cuales iban encaminadas a formalizar una autonomía estaban intentando concretar desde unas décadas atrás.

\section{Recapitulación}

Es importante mencionar que ninguno de los diputados electos por San Luis Potosí entre 1810 y 1814 logró participar en las Cortes, diversas razones impidieron que llegaran a la península. También debemos decir que ninguno de los puntos presentados en las Instrucciones fue atendido, y prácticamente ninguna de las peticiones de otras provincias americanas fue aprobada. Esto no resta importancia a los documentos que presentamos en este artículo. Creemos haber mostrado que son documentos invaluables para analizar las aspiraciones autonomistas de los americanos y que éstas no eran producto de la coyuntura de 1808. Los puntos tratados por diversos ayuntamientos en nombres de sus provincias que se enuncian en los dos cuadros presentaros en este artículo muestran de manera clara esos deseos, y con toda seguridad su análisis puntual daría más luz sobre el tema.

Indudablemente ese análisis requiere abrevar de muchas más fuentes, pero también resulta fundamental rastrear esas peticiones y analizar el contexto en el que surgieron. Ya lo señalamos, estos documentos proporcionan varias pistas para realizar ese ejercicio, y un punto de partida es la revisión de las actas de cabildo; en ellas podemos conocer la manera como asumieron la implementación del sistema de intendencias, y las acciones que emprendieron para defender sus prerrogativas, y aún ampliarlas aprovechando la nueva jerarquía territorial que les daba ser capital de intendencia; en gran medida esto los impulsó a buscar beneficios. En las actas de cabildo también podemos seguir la manera como asumieron la crisis monárquica. En

\footnotetext{
${ }^{53}$ El aumento de las diputaciones provinciales fue un tema recurrente desde la primera convocatoria de las cortes de 1820. La Constitución de Cádiz disponía la creación de diputaciones provinciales; en la Nueva España se autorizaron seis durante el primer periodo gaditano, si bien no todas lograron instalarse, como fue el caso de San Luis Potosí. Los diputados americanos consideraban que este número no era suficiente. Miguel Ramos Arizpe, diputado por Coahuila, era el más insistente en esta idea y, junto con Mariano Michelena, el 4 de octubre presentó a las Cortes una iniciativa en la que, entre otras cosas, pedían la creación de una diputación en Michoacán, a la que se agregaría Guanajuato. Las resoluciones oficiales no parecieron haber llegado a Nueva España antes de que se declarara la independencia. BENSON, Nettie Lee. La Diputación Provincial y el federalismo mexicano. México: El Colegio de México, UNAM, 2012, pp. 82-123.
} 
ese sentido, resulta fundamental conocer el proceso de elaboración de las Instrucciones porque nos permite observar una variedad de aspiraciones personales y corporativas que, aun cuando no se incluyeron, dejan ver cómo visualizaban la ciudad y la provincia.

Finalmente, debemos decir que en esos documentos encontramos declaraciones que ratifican esos deseos autonomistas y, sobre todo, la convicción de que sus demandas serían atendidas; así lo evidencian los representantes del cuerpo de minería de San Luis Potosí cuando aseguraban que la Junta Central, en nombre del monarca estaba "dando a manos llenas todas las indulgencias justas y necesarias" "54. Ellos mismos nos descubren el principal objetivo de las instrucciones al decir que si se les concedía lo que estaban pidiendo, no tendrían nada que envidiarle a la metrópoli de México. Consideramos que un análisis puntual de las Instrucciones de las demás provincias mostraría que, en su mayoría, iban en ese camino.

\section{Fuentes}

\subsection{Documentales}

ABAD Y QUEIPO, Manuel. Representación sobre la inmunidad personal del clero, reducida por las leyes del nuevo código, en el cual se propuso al rey el asunto de diferentes leyes que establecidas harían la base principal de un gobierno liberal y benéfico para la América y para su metrópoli. En: ABAD Y QUEIPO, Manuel. Colección de los escritos más importantes que en diferentes épocas dirigió al gobierno d. Manuel Abad y Queipo, obispo electo de Michoacán, México: En la Oficina de Mariano Ontiveros, 1813, pp. 1-65.

Instrucción que, en cumplimiento de la Real Orden de 22 de enero del presente año de 1809, librada por la Suprema Junta Central depositaria de la autoridad Soberana el Ayuntamiento de SLP al Exmo. Sr. D. Miguel de Lardizábal, diputado representante por la Nueva España y vocal de dicha Suprema Junta en AHESLP, Ayuntamiento de San Luis Potosí, Actas de cabildo, 24 de agosto de 1809.

Adiciones a las Instrucciones que presenta el ayuntamiento de San Luis Potosí para sus diputados a Cortes, en AHESLP, Ayuntamiento de San Luis Potosí, Actas de cabildo, 19 de abril de 1812.

Instrucciones que proponen los procuradores Pedro Fernández y Cayetano Díaz Bracamonte, para extender las que hayan de darse a los señores Diputados en Cortes por la Provincia de San Luis Potosí, en AHESLP, Ayuntamiento de San

\footnotetext{
${ }^{54}$ AHESLP, Ayuntamiento de San Luis Potosí, Actas de cabildo, 1809, Propuesta que presentan Ignacio de Astegui y Pedro Manuel de Castro, a nombre del Noble y Leal Gremio de la Minería, al ayuntamiento de San Luis Potosí para elaborar las instrucciones.
} 
Luis Potosí, Actas de cabildo, 17 de noviembre de 1820.

\subsection{Bibliográficas}

ALMARZA, Ángel y Armando MARTÍNEZ (eds.). Instrucciones para los diputados del Nuevo Reino de Granada y Venezuela ante la Junta Central Gubernativa de España e Indias. Bucaramanga: Universidad Industrial de Santander, 2008. 266 p.

ÁVILA, Alfredo y Pedro PÉREZ HERRERO (coords.). Las experiencias de 1808 en Iberoamérica. México: Universidad de Alcalá, UNAM, 2008.

BENSON, Nettie Lee. La Diputación Provincial y el federalismo mexicano. México: El Colegio de México, UNAM, 2012.

BERNAL RUIZ, Graciela. Sin quedarle qué envidiar a la metrópoli de México. Las aspiraciones políticas de una provincia novohispana, San Luis Potosí, 17861821. Zamora: El Colegio de Michoacán; El Colegio de San Luis; Universidad de Guanajuato; Universidad Jaume I, 2019.

BERNAL RUIZ, Graciela. El ayuntamiento de San Luis Potosí durante la crisis monárquica. Expectativas y realidades (1808-1814). En: HENSEL, Silke (coord.). Constitución, poder y representación. Dimensiones simbólicas del cambio político en la época de la independencia mexicana. Madrid: Iberoamericana; Frankfurt am Main: Vervuert; México: Bonilla Artigas, 2011, pp. 241-275.

BERNAL RUIZ, Graciela. En búsqueda de una descentralización. San Luis Potosí en la coyuntura de la crisis monárquica. En: ORTIZ, Juan y FRASQUET, Ivana (eds.). Jaque a la Corona. La cuestión política en las independencias Iberoamericanas. Castellón: Universitat Jaume I, 2010, pp. 57-77.

CARMAGNANI, Marcelo. Territorios, provincias y estados: Las transformaciones de los espacios políticos en México, 1750-1850. En: VÁZQUEZ, Josefina. La fundación del Estado Mexicano. Nueva Imagen,1994.

CASTILLO, Francisco. Las Cortes de Cádiz y la imagen de América: la visión etnográfica y geográfica del Nuevo Mundo. Cádiz: Universidad de Cádiz, 1994.

CHUST, Manuel. La cuestión nacional americana en las Cortes de Cádiz, 18101814. Valencia: Centro Francisco Tomás y Valiente; UNED Alzira; Fundación Instituto Historia Social; UNAM; IIH, 1999.

CHUST, Manuel. (coord.). La eclosión juntera en el mundo hispano. México: El Colegio de México; FCE, 2007.

ESCAMILLA, Iván. La representación política en Nueva España: del antiguo régimen al advenimiento de la nación. Historias. May./ago. 2000, n. 46, pp. 23-43. 
FERRER, Manuel. La constitución de Cádiz y su aplicación en la Nueva España. México: UNAM; IIJ, 1993.

FLORESCANO, Enrique y GIL, Isabel. Descripciones económicas generales de Nueva España, 1784-1817. México: SEP; INAH, 1973.

FLORESCANO, Enrique y GIL, Isabel. Descripciones económicas regionales de Nueva España. Provincias del norte, 1790-1814. México: INAH; SEP, 1976.

GARRIGA, Carlos. Gobierno y justicia: El gobierno de la justicia. En: La jurisdicción contencioso administrativa en España. Una historia de sus orígenes. VII. Madrid: Consejo General del Poder Judicial, 2008, pp. 47-113. [Cuadernos de Derecho Judicial].

GUERRA, Francois-Xavier. Modernidad e independencia. México: FCE, 2000.

PIETSCHMANN, Horst. Las Reformas Borbónicas y el sistema de Intendencias en Nueva España. Un estudio político administrativo. México: FCE, 1996.

PORTILLO, José María. Crisis Atlántica. Autonomía e Independencia en la crisis de la monarquía hispana. Madrid: Marcial Pons; Fundación Carolina, 2006.

RODRÍGUEZ, Jaime. Las independencias de la América española. México: FCE; EI Colegio de México, 1996.

RIEU-MILLAN, Marie-Laure. Los diputados americanos en las Cortes de Cádiz: igualdad o independencia. Madrid: CSIC, 1990.

ROJAS, Beatriz. Documentos para el estudio de la cultura política de la transición: juras, poderes e instrucciones, Nueva España y la Capitanía General de Guatemala, 1808-1820. México: Instituto Mora, 2005.

TIENDA DE CUERVO, José. Estado general de las fundaciones hechas por $d$. José Escandón en la colonia del Nuevo Santander. Tomo II. México: Talleres gráficos de la Nación, 1929.

VÁZQUEZ, Josefina. La fundación del Estado Mexicano. México: Nueva Imagen,1994. 